\title{
Internal Rotation in Tolane: Molecular Structure in Gas and Crystal Phases
}

\author{
A. V. Abramenkov, ${ }^{a}$ A. Almenningen, ${ }^{b}$ B. N. Cyvin, ${ }^{c}$ S. J. Cyvin, ${ }^{c}$ T. Jonvik, ${ }^{b}$ \\ L. S. Khaikin, ${ }^{a}$ C. Rømming ${ }^{b}$ and L. V. Vilkov ${ }^{a}$ \\ a Department of Chemistry, Moscow State University, 119899 GSP Moscow V-234, USSR, ${ }^{b}$ Department of \\ Chemistry, University of Oslo, $\mathrm{N}-0315$, Oslo 3 and ${ }^{\circ}$ Division of Physical Chemistry, University of Trondheim, \\ N-7034 Trondheim NTH, Norway
}

\begin{abstract}
Abramenkov, A. V., Almenningen, A., Cyvin, B. N., Cyvin, S. J., Jonvik, T., Khaikin, L. S., Rømming, C. and Vilkov, L. V., 1988. Internal Rotation in Tolane: Molecular Structure in Gas and Crystal Phases. - Acta Chem. Scand., Ser. A 42: 674-684.

The molecular structure of tolane (diphenylacetylene) was studied by electron diffraction in the gas phase at $150^{\circ} \mathrm{C}$ and by $\mathrm{X}$-ray crystallography at $-150^{\circ} \mathrm{C}$. Electron diffraction analysis involved a dynamic model within the framework of the $r_{\mathrm{a}}$ approximation. The potential function for internal rotation, $V(\varphi)$, was determined in two different ways: (1) on the basis of analytical expressions for the potential as a truncated Fourier expansion, including 1 or 2 terms, and (2) by numerical solution of the integral equation for the probability density $W(\varphi)$, applying the Tikhonov regularization method. However, an unambiguous determination of the $V(\varphi)$ parameters proved impossible.

As in earlier X-ray studies, the tolane conformation in the crystal was found to be planar. However, owing to the lower temperature in the present experiment the nuclear positions were determined more precisely. The geometrical parameters are (gas/crystal): $C \equiv C$ 1.215(6)/1.212(5); average C-C 1.400(2)/1.399(3); $\mathrm{C}-\mathrm{C} \equiv 1.417(5) / 1.426(3) \AA ; \angle \mathrm{C}_{\text {ipso }} 119.3(7) / 119.4(3) ; \angle \mathrm{C}_{\text {ortho }} 120.8(6) / 120.1(3)$; and $\angle \mathrm{C}-\mathrm{C} \equiv \mathrm{C} 180^{\circ}$ (ass) $/ 178.0(2)^{\circ}$.
\end{abstract}

Dedicated to Professor Otto Bastiansen on his 70th birthday

The phenyl rings of the tolane molecule are sufficiently separated from each other for the steric interaction between them to be practically ruled out. Hence, the shape of the rotation protential for an isolated molecule mainly depends on conjugation between the unsaturated fragments. A planar equilibrium geometry $\left(D_{2 \mathrm{~h}}\right.$ symmetry) may result from overlapping $p \pi$-orbitals of both phenyl rings with the same $p \pi$-orbital of the $\mathrm{C} \equiv \mathrm{C}$ fragment. Preferential interaction of the aromatic ring $\pi$-systems with different $C \equiv C$ $p \pi$-orbitals would lead to stabilization of the perpendicular molecular form ( $D_{2 \mathrm{~d}}$ symmetry). Finally, if both forms are roughly similar in energy the internal rotation of phenyl substituents would be close to free.

Based on the two-dimensional Hückel molecular orbital theory, the calculation of the total $\pi$-electron energies for $D_{2 \mathrm{~h}}$ and $D_{2 \mathrm{~d}}$ conformations of the tolane molecule predicts that the planar structure is somewhat more stable than the perpendicular one $\left(\Delta E_{\pi}=0.03 \beta \approx-0.6 \mathrm{kcal}\right.$ $\left.\mathrm{mol}^{-1}\right) .{ }^{1}$ The small difference in energy gives an indication of relatively unhindered rotation. A similar conclusion is suggested by the CNDO, $\mathrm{INDO}^{2}$ and $\mathrm{CNDO} / 2^{3}$ calculations, although in contrast to the Hückel calculations the perpendicular form is predicted to be the more stable (by $0.4-0.7 \mathrm{kcal} \mathrm{mol}^{-1}$ ).

The experimental data available are not sufficient for an unambiguous characterization of the rotation potential. Nevertheless, the estimates of barrier heights and some other results indicate that the internal rotation in the tolane molecule is only slightly hindered:

From the values of the Henry constant for tolane adsorbed on graphitized carbon black as measured experimentally and calculated by semiempirical molecular statistical methods, Grumada et al. ${ }^{4}$ concluded that the planar conforma- 
tion is less stable; however, the energy of the perpendicular form is lower by only $0.6 \mathrm{kcal}$ $\mathrm{mol}^{-1} \cdot{ }^{4}$

The results of an analysis of the electronic spectra of tolane in a supersonic free jet have recently been published. These are also in conformity with the hypothesis of quasi-free rotation of phenyl rings about the $\mathrm{C}-\mathrm{C}$ bonds. ${ }^{5} \mathrm{On}$ the basis of these data, assuming that the potential function is of the simplest form i.e. $V(\varphi)=$ $\frac{1}{2} V_{2}(1-\cos 2 \varphi)$, the height of the barrier was found to be $V_{2}=0.58 \mathrm{kcal} \mathrm{mol}^{-1}$. The above potential permits adequate description not only of frequencies but also of the intensity distribution in the observed fluorescence spectra.

According to X-ray diffraction data ${ }^{3,6,7}$ obtained at room temperature, the tolane molecule in the crystal has a planar conformation. However, Refs. 3 and 7 report considerable differences between the two crystallographically independent molecules with respect to deviations of the atoms from the least-squares plane ( $\pm 0.024-0.027$ and $\pm 0.002-0.004 \AA)$. The authors of Ref. 7 believe that greater deviations correspond to a certain increase in libration about the longitudinal axis of the molecule. The stabilization of the planar conformation of the tolane molecule in the crystal may result from the Van der Waals interactions, and the noted disorder reflects the absence of a deep minimum in this region of the internal rotation potential curve.

The molecular conformation of tolane in solution has been repeatedly discussed in various spectral works. Electronic absorption spectra $^{8}$ and Raman spectra ${ }^{9}$ have indicated that planar geometry is the most probable. On the whole, the same conclusion is reached by Baranovic et al. in their analysis of the vibrational spectra of tolane. ${ }^{10}$ However, some facts inexplicable on the basis of the $D_{2 \mathrm{~h}}$ model, in particular the observed excess of polarized Raman lines, may be related to the presence of some proportion of non-planar molecules. ${ }^{10}$

Analysis of Raman line intensities for a number of polyphenyl derivatives indicates that transition of the crystalline state to liquid brings about a disturbance of the co-planarity of tolane phenyl groups. ${ }^{11}$ This conclusion is in agreement with the above-mentioned interpretation of data given in Ref. 10.

The purpose of the present work was further study of the molecular structure and the internal rotation in the tolane molecule. The gas-phase study was performed by the electron diffraction method at $150^{\circ} \mathrm{C}$. The tolane molecule structure in the crystalline phase was determined by the $\mathrm{X}$-ray method at $-150^{\circ} \mathrm{C}$.

The above-considered results indicate that the most adequate description of electron diffraction data for tolane may be provided by a dynamic model which accounts for large amplitude motion (see below). It should be noted that preliminary analysis of our electron diffraction data within the framework of a static model has not permitted an unambiguous choice of optimum conformation, and only showed that the perpendicular model of $D_{2 \mathrm{~d}}$ symmetry $\left(\varphi=90^{\circ}\right)$ provides a worse fit to the experimental data. ${ }^{4,12}$ At that stage, an attempt at analysis within a dynamic model with a potential in the form $V(\varphi)=\frac{1}{2} V_{2}(1$ $\cos 2 \varphi$ ) also failed owing to the low sensitivity of the fitness factor to the magnitude of the $V_{2}$ parameter. One reason is inadequacy of the force field used in Refs. 4 and 12 for calculation of mean amplitudes: for some $\mathrm{C} \cdots \mathrm{C}$ distances that are rotation-dependent, mean amplitudes of framework vibrations exceeded $0.30 \AA$, i.e. were beyond reasonable limits. For refining the tolane force field, normal coordinate analysis was required. ${ }^{13}$

\section{Experimental}

A commercial tolane sample was used in the experiments.

Electron diffraction data. The electron diffraction pattern was recorded and preliminary treatment of experimental data were performed at Oslo University. ${ }^{14,15}$ The experimental conditions and the principal characteristics of the data used are presented in Table 1 . Wavelength calibration was based on benzene data.

According to the analysis technique adopted at Moscow University, the averaged curves of total intensity were used to calculate the molecular intensity curves $s M^{\exp }(s)$ (Fig. 1).

The background lines were drawn graphically through oscillations of the total intensity curves to obtain a smooth curve and adjusted during the refinements. The calculations of theoretical curves were based on the atomic factors for elastic scattering taken from the tables by Bonham 


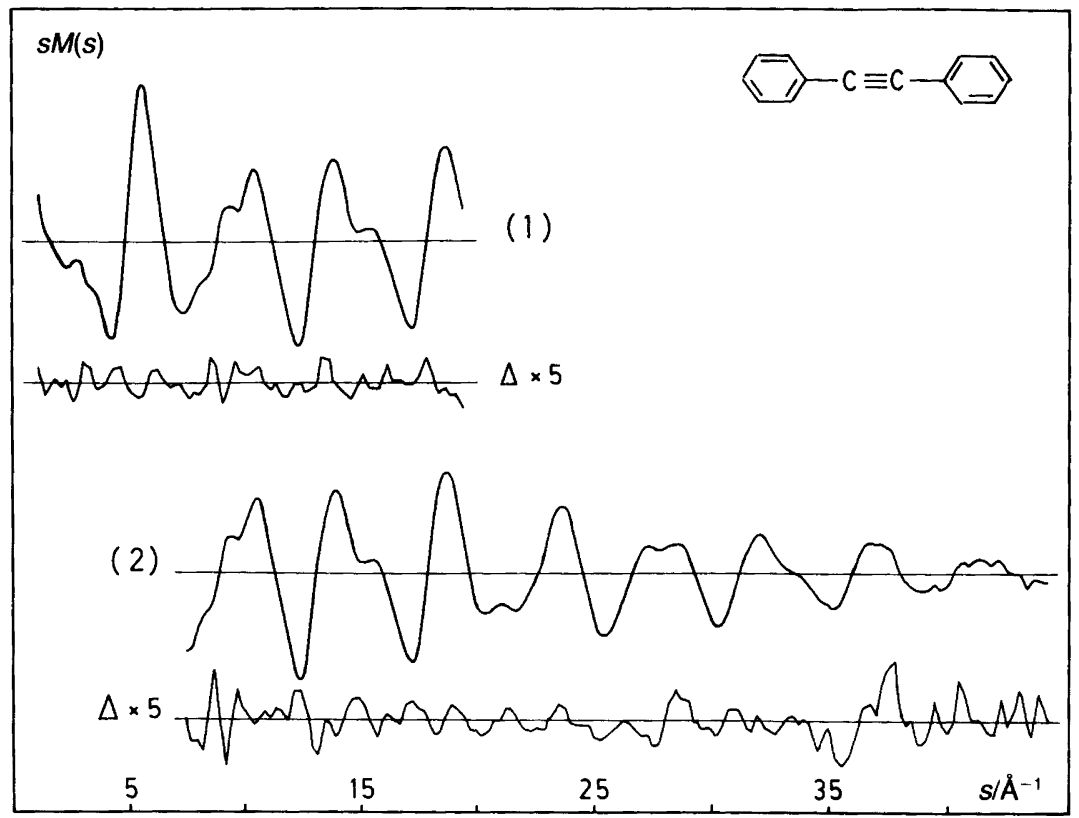

Fig. 1. The experimental $M^{\exp }(s)$ curves for tolane obtained from the two camera distances (1 and 2) and the difference curves $\Delta=s M^{\exp }(s)-K_{D} s_{M}{ }^{\text {theor }}(s)$ for Model I (Table 5). The difference curves for Models II and III have no specific features compared with those for Model I.

and Schäfer, ${ }^{16}$ and the inelastic scattering factors taken from tables by Tavard. ${ }^{17}$ Experimental data are available from the authors upon request.

$X$-ray diffraction data. Crystals were formed by recrystallization from warm methanol. The speci- mens used in the experiments had approximate dimensions $0.3 \times 0.3 \times 0.4 \mathrm{~mm}$. The diffraction data were collected on a SYNTEX $P \overline{1}$ diffractometer using graphite crystal monochromated Mo $K \alpha$ radiation $(\lambda=0.71069 \AA)$; the temperature at the crystal site was kept at $-150^{\circ} \mathrm{C}$. Cell

Table 1. Conditions of the electron diffraction experiment and principal characteristics of the intensity data obtained.

\begin{tabular}{lll}
\hline & Camera distance & \\
\cline { 2 - 3 } & Long $(L=479.25 \mathrm{~mm})$ & Short $(L=196.13 \mathrm{~mm})$ \\
\hline Nozzle temperature $/ \mathrm{C}$ & 150 & 150 \\
Electron wave lenght $/ \AA$ & 0.06468 & 0.06468 \\
Number of photo-plates & 5 & 3 \\
Scattering angles, $s / \AA^{-1}$ & $1.250 \leqslant s \leqslant 19.625$ & $7.50 \leqslant s \leqslant 44.25$ \\
Data interval, $\Delta s / \AA^{-1}$ & 0.125 & 0.25 \\
Weight scheme constants: & 3.0 & 8.0 \\
$s_{1} / \AA^{-1}$ & 15.0 & 20.0 \\
$s_{2} / \AA^{-1}$ & 0.05 & 0.10 \\
$W_{1} / \AA^{2}$ & 0.02 & 0.0025 \\
$W_{2} / \AA^{2}$ & & \\
\hline
\end{tabular}

asee Ref. 15. 
Table 2. Crystal data for tolane at $-150^{\circ} \mathrm{C}$.

$\begin{array}{lc}\text { Monoclinic, space group } P 2_{1} / c \text { (No. 14) } \\ a / \AA & 15.204(3) \\ b / \AA & 5.685(2) \\ c / \AA & 12.721(6) \\ \beta /{ }^{\circ} & 113.90(3) \\ V / \AA^{3} & 1005.3(6) \\ Z & 4 \\ M & 178.23 \\ D_{x} / \mathrm{g} \mathrm{cm}^{-3} & 1.178\end{array}$

parameters were determined by a least-squares fit to the diffractometer settings for 15 general reflections. The crystal data are given in Table 2 .

A unique set of intensities was recorded using the $\theta / 2 \theta$ scan mode with a scan rate of $3-8^{\circ} \mathrm{min}^{-1}$ $(2 \theta)$, depending on the intensity. The scan range was from $1.2^{\circ}$ below $2 \theta\left(\alpha_{1}\right)$ to $1.2^{\circ}$ above $2 \theta\left(\alpha_{2}\right)$; background counts were measured for 0.35 times the scan time at each of the scan limits. Of the measured reflections with $\sin \theta / \lambda<0.76 \AA^{-1}, 2636$ had intensities larger than twice their estimated standard deviation. Three standard reflections measured for every 100 reflections showed no systematic variation. The intensities were corrected for Lorentz and polarization effects but not for absorption.

\section{Structure analysis of the electron diffraction data}

Dynamic model. It is believed that framework vibrations and torsion vibrations can be separated. The relative weights or probabilities of particular $\varphi$ values, $P(\varphi)$, are normally determined, assuming a Boltzmann distribution of $\varphi$ probability density: $W(\varphi)=k \exp (-V(\varphi) / R T)$. The rotation potential $V(\varphi)$ is expressed in the parametric form as a finite series with a small number of terms, for example the Fourier series (see Ref. 18).

However, it is often difficult or even impossible to set $a$ priori the number of expansion terms needed. By arbitrarily truncating the series, we introduce into the probability distribution concerned the limitations peculiar of the analytical $V(\varphi)$ expression used.

In the present study the idea of numerical determination of $W(\varphi)$ from the integral equation $\int_{0}^{2 \pi} s M(s, \varphi) W(\varphi) \mathrm{d} \varphi=s M^{\exp }(s), s \in\left[s_{\min }, s_{\max }\right]$

was derived. ${ }^{19}$ Here $s_{\min }$ and $s_{\max }$ are limits of the generalized coordinate of scattering, $s M(s, \varphi)$ (approximation of the scattering intensities by a pseudoconformer with the $\varphi$ rotation angle) and $s M^{\exp }(s)$ (experimental molecular intensities).

According to the regularization method, the solution to an extremal problem

$$
\begin{aligned}
& \min _{W(\varphi)}\left\{\Phi_{\alpha}[W(\varphi)]=\right. \\
& \int_{s_{\min }}^{s_{\max }}\left[\int_{0}^{2 \pi} W(\varphi) s M(s, \varphi) \mathrm{d} \varphi-s M^{\exp }(s)\right]^{2} \mathrm{ds} \\
& \left.+\left[\alpha \int_{0}^{2 \pi} W^{2}(\varphi)+\left(\frac{\mathrm{d} W(\varphi)}{\mathrm{d} \varphi}\right)^{2}\right] \mathrm{d} \varphi\right\}
\end{aligned}
$$

is accepted as an approximate solution, where $\alpha$ is the numerical parameter of regularization $(\alpha>$ $0)$.

There is one unique solution converging to a precise solution with a tendency for the experimental data error to approach zero if there is a certain correspondence of the $\alpha$ parameter and the data error. ${ }^{19,20}$

A sub-routine was produced which implements this technique within the KCED25 program. $^{21}$ The results of the evaluation of the tolane molecule rotation potential as expressed parametrically, and the numerical solution to the integral equation are compared and analyzed below.

Calculation of mean amplitudes of vibration. At the preliminary stage of the analysis of the electron diffraction data for the tolane molecule, ${ }^{4,12}$ the procedure for the biphenyl molecule ${ }^{22}$ was followed for the calculation of mean amplitudes. The approximations of force fields developed for planar $^{23}$ and non-planar ${ }^{24}$ vibrations of condensed aromatic compounds were adapted. However, the approximation does not take any account of the torsion force constant for the mutual rotation of the phenyl rings, which is especially uncertain. The value 0.05 mdyn $\AA^{-1}$ was chosen somewhat arbitrarily. Also, both linear bending force constants (for in-plane and out-of-plane vibrations) viz. 0.5 mdyn $\AA^{-1}$, are rather uncertain. For the $D_{2 \mathrm{~h}}$ model the initial force field was then refined by fitting the calculated frequencies to experi- 
mental values. ${ }^{9,25}$ The refined force field was used to obtain the estimates of the mean amplitudes of vibration $\left(u_{i j}\right.$ and $u_{i j}^{\mathrm{fr}}$, where the superscript stands for "framework") at $150^{\circ} \mathrm{C}$. The perpendicular amplitude corrections $\left(K_{i j}\right.$ and $\left.K_{i j}^{\mathrm{fr}}\right)$ were also calculated, but are assumed to be dubious, mainly because of the uncertainty of the torsional force constant and possibly because of the breakdown of the harmonic vibration approximation. A corresponding calculation was performed for the $D_{2 \mathrm{~d}}$ and $D_{2}\left(\varphi=45^{\circ}\right)$ models, assuming the force constants to be transferable. The parameters of the framework vibrations, $u_{i j}^{\mathrm{fr}}$ and $K_{i j}^{\mathrm{fr}}$, were calculated for five pseudoconformers of tolane with $\varphi$ angles equally spaced between 9 and $81^{\circ}$ (see also below). Specifically, the $\varphi$ values are: $9,27,45,63$ and $81^{\circ}$.

For internuclear distances independent of the rotation angle $\varphi$, the $u_{i j}^{\mathrm{fr}}$ and $u_{i j}$ estimates were presumed to be reliable and were therefore used in the subsequent analysis. In order to avoid the unreliable $K_{i j}$ and $K_{i j}^{\mathrm{fr}}$ values, the structure analysis of electron diffraction data was performed within the framework of the $r_{\mathrm{a}}$ approximation.

The values of $u_{i j}$ and $u_{i j}^{\mathrm{fr}}$ at the temperature of the experiment $\left(150^{\circ} \mathrm{C}\right)$ and which were used in the analysis are given in Tables 3 and 4 together with the values of the respective distances $r_{i j}$. For the $\varphi$-dependent distances only the data for three selected angles are included in Table 4 for the sake of brevity.

Refinement. With respect to the geometry of the tolane molecule the following limitations were assumed: (a) all $\mathrm{C}-\mathrm{C}$ bond lengths in the phenyl rings are equal; (b) all $\mathrm{C}-\mathrm{H}$ bond lengths are equal and each bond is directed so as to bisect the respective endocyclic $\mathrm{CCC}$ angle; (c) the central fragment $>\mathrm{C}-\mathrm{C} \equiv \mathrm{C}-\mathrm{C}<$ is linear; (d) the phenyl fragments have $C_{2 v}$ symmetry.

Owing to the symmetry of the potential function $V(\varphi)$ for tolane, it is sufficient to consider the $\varphi$ angle range between 0 and $90^{\circ}$. This range was divided into five sub-ranges. Assuming the independence of geometry of the rotation, the description of such pseudo-conformers required six independent geometrical parameters: $\mathrm{C} \equiv \mathrm{C}$ and $>\mathrm{C}-\mathrm{C} \equiv$ bond lengths, the weighted average $(\mathrm{C}-\mathrm{C})_{\mathrm{av}}$ and $(\mathrm{C}-\mathrm{H})_{\mathrm{av}}$ bond lengths, and endocyclic valence angles at the ipso and ortho carbon atoms. The starting values for these parameters were taken from Refs. 4 and 12 (see Table 8).
Table 3. Calculated mean amplitude values at $150^{\circ} \mathrm{C}$ for the carbon-carbon distances of the tolane molecule independent of the rotation angle (in $\AA$ ). ${ }^{a}$

\begin{tabular}{|c|c|c|}
\hline Distance & $r_{a}$ & $u=u^{t r}$ \\
\hline $\begin{array}{l}\mathrm{C} \equiv C \\
\equiv C-C_{<} \\
C_{1} \cdots C_{2} \\
C_{2} \cdots C_{3} \\
C_{3} \cdots C_{4} \\
(C H)_{a^{\prime}} \\
C_{1} \cdots C_{3} \\
C_{2} \cdots C_{4} \\
C_{3} \cdots C_{5} \\
C_{2} \cdots C_{6} \\
C_{2} \cdots C_{5} \\
C_{1} \cdots C_{4} \\
C_{2} \cdots C_{1^{\prime}} \\
C_{3} \cdots C_{1^{\prime}} \\
C_{4} \cdots C_{1^{\prime}} \\
C_{2} \cdots C_{4^{\prime}} \\
C_{3} \cdots C_{4^{\prime}} \\
C_{4} \cdots C_{4^{\prime}} \\
C_{1} \cdots C_{4^{\prime}} \\
C_{1} \cdots C_{7^{\prime}} \\
C_{2} \cdots C_{7} \\
C_{2} \cdots C_{7^{\prime}} \\
C_{3} \cdots C_{7} \\
C_{3} \cdots C_{7^{\prime}} \\
C_{4} \cdots C_{7} \\
C_{4} \cdots C_{7^{\prime}}\end{array}$ & $\begin{array}{l}1.215(2) \\
1.417(2) \\
1.400\left(0_{4}\right) \\
\text { average } \\
1.070(2) \\
2.435(2) \\
2.412(3) \\
2.439(4) \\
2.416(3) \\
2.802(3) \\
2.795(5) \\
4.907(3) \\
6.276(3) \\
6.844(5) \\
7.647(5) \\
9.034(5) \\
9.638(9) \\
4.049(3) \\
2.632(2) \\
2.444(2) \\
3.551(2) \\
3.729(2) \\
4.893(2) \\
4.212(4) \\
5.427(4)\end{array}$ & $\begin{array}{l}0.036 \\
0.048 \\
0.048 \\
0.048 \\
0.047 \\
0.077 \\
0.058 \\
0.058 \\
0.056 \\
0.056 \\
0.063 \\
0.061 \\
0.117 \\
0.107 \\
0.078 \\
0.147 \\
0.136 \\
0.088 \\
0.062 \\
0.052 \\
0.076 \\
0.097 \\
0.075 \\
0.088 \\
0.070 \\
0.072\end{array}$ \\
\hline
\end{tabular}

${ }^{a}$ For distances independent of the rotation angle $u_{i j}^{\text {tr }}$ are practically equal to $u_{i j}$ (see text). The values of mean amplitudes given here were used in the electron diffraction analysis as fixed parameters. Numbering of atoms as in Fig. 2. Least-squares standard deviations are given in parentheses.

The calculated mean amplitudes were not refined.

Co-variation of the independent geometrical parameters performed within the $r_{\mathrm{a}}$ approximation proceeded without difficulty. Their values were not at all affected by the values of the parameters of the potential functions. This can be illustrated by the correlation matrix for Model I with parametric representation of the potential as $V(\varphi)=\frac{1}{2} V_{2}(1-\cos 2 \varphi)$ (Table 9). It should be noted that elements of correlation matrices for models I to III are practically identical, in agreement with the invariance of refined geometrical parameters for these models. The dependent dis- 
Table 4. Calculated values of mean amplitudes of the framework vibrations $u^{\text {fr }}$ for distances of the tolane molecule depending on the rotation angle, and respective $u$ values for the models of $D_{2 h}\left(\varphi=0^{\circ}\right)$ and $D_{2}(\varphi=$ $45^{\circ}$ ) symmetries (in $\AA$ ). ${ }^{a}$ Temperature $150{ }^{\circ} \mathrm{C}$.

\begin{tabular}{|c|c|c|c|c|c|c|c|c|}
\hline \multirow[t]{2}{*}{ Distance } & \multicolumn{2}{|l|}{$\varphi=9^{\circ}$} & \multicolumn{2}{|l|}{$\varphi=45^{\circ}$} & \multicolumn{2}{|l|}{$\varphi=81^{\circ}$} & \multicolumn{2}{|c|}{$u$ for models: } \\
\hline & $r_{\mathrm{a}}$ & $u^{f r}$ & $r_{\mathrm{a}}$ & $u^{\pi}$ & $r_{\mathrm{a}}$ & $u^{\mathrm{fr}}$ & $D_{2 \mathrm{~h}}$ & $D_{2}$ \\
\hline$C_{1} \cdots C_{6}$ & $5.971(3)$ & 0.1077 & $5.902(3)$ & 0.1437 & $5.764(3)$ & 0.1136 & 0.1255 & 0.1485 \\
\hline$C_{1} \cdots C_{7}$ & $7.278(4)$ & 0.1042 & $7.220(4)$ & 0.1419 & $7.107(4)$ & 0.1125 & 0.1212 & 0.1462 \\
\hline$C_{1} \cdots C_{9}$ & $6.866(4)$ & 0.1001 & $6.926(4)$ & 0.1847 & $7.042(4)$ & 0.1026 & 0.1944 & 0.1868 \\
\hline$C_{1} \cdots C_{10}$ & $5.467(4)$ & 0.0962 & $5.541(4)$ & 0.1804 & $5.684(4)$ & 0.1009 & 0.1912 & 0.1832 \\
\hline $\mathrm{C}_{2} \cdots \mathrm{C}_{7}$ & $8.613(4)$ & 0.1031 & $8.565(4)$ & 0.1366 & $8.469(4)$ & 0.1127 & 0.1128 & 0.1407 \\
\hline $\mathrm{C}_{2} \cdots \mathrm{C}_{9}$ & $8.265(4)$ & 0.1033 & $8.316(4)$ & 0.1874 & $8.414(4)$ & 0.1042 & 0.1975 & 0.1889 \\
\hline
\end{tabular}

aNumbering of atoms as in Fig. 2. Least-squares standard deviations are given in parentheses. The $u^{\mathrm{tr}}$ values given here were used in the electron diffraction analysis as fixed parameters.

Table 5. Results of refinement of the potential function to internal rotation for tolane.

\begin{tabular}{llll}
\hline Parameters $^{a}$ & $\begin{array}{l}\text { Model I } \\
V(\varphi)=V_{2} / 2(1-\cos 2 \varphi)\end{array}$ & $\begin{array}{l}\text { Model II } \\
V(\varphi)=V_{2} / 2(1-\cos 2 \varphi) \\
+V_{4} / 2(1-\cos 4 \varphi)\end{array}$ & $\begin{array}{l}\text { Model III } \\
\text { Numerical solution for } \\
\text { probability density } W(\varphi)\end{array}$ \\
\hline$V_{2}$ & $0.59(27)$ & $0.88(67)$ & \\
$V_{4}$ & & -2.07 fixed & \\
$\varphi_{\min }$ & 0.0 & $42.0^{b}$ & 40 \\
$V\left(0^{\circ}\right)-V\left(\varphi_{\min }\right)$ & & 1.65 & 2 \\
$V\left(90^{\circ}\right)-V\left(\varphi_{\min }\right)$ & 0.59 & 2.53 & $>2$ \\
$f_{\text {tors }}$ & $0.008^{c}$ & $0.114^{c}$ & 5.36 \\
$R(\%)$ & 5.50 & 5.39 & \\
\hline
\end{tabular}

a Values of potential energy $V(\varphi)$ and parameters $V_{2}$ and $V_{4}$ in $\mathrm{kcal} \mathrm{mol}^{-1}$; the uncertainty corresponds to the least-squares standard deviation; $R=100\left[\Sigma_{j} w_{j j} \Delta_{j}^{2} / \Sigma_{j} w_{i j}\left\{s_{j} M^{\exp }\left(s_{j}\right)\right\}^{2}\right]^{1 / 2}$, where $\Delta_{j}=s_{j} M^{\exp }\left(s_{j}\right)-K_{L} s_{j} M^{\text {theor }}\left(s_{j}\right)$ and $w_{j j}$ is a diagonal weight function as specified in Table 1. ${ }^{b}$ Location of potential function minimum $\varphi_{\min }=0.5$ arccos $\left(-V_{2} / 4 V_{4}\right)$ (in degrees). ${ }^{c}$ Torsional force constant $f_{\text {tors }}=\left(\frac{\delta^{2} V(\varphi)}{\delta \varphi^{2}}\right)_{\varphi=\varphi_{\min }}$ (in mdyn $\cdot \AA^{-1}$ ).

tances are presented in Tables 3 and 4 along with respective mean amplitudes.

Intially the analytical form of the rotation potential included one term of a Fourier expansion with a $V_{2}$ parameter (Model I, Table 5). In this approximation the position of the potential minimum was assumed $a$ priori to be at $\varphi=0^{\circ}$, corresponding to the equilibrium structure of the tolane molecule being planar. The barrier height of $0.59(27) \mathrm{kcal} \mathrm{mol}^{-1}$ thus obtained in the perpendicular conformation is in good agreement with pusblished data (see the introduction).

Further, another term with the $V_{4}$ parameter was added to the analytical form of the potential
(Model II, Table 5). However, variation of the $V_{4}$ parameter, either along with or independently of $V_{2}$, did not result in a stable solution. Hence, several variations were tested in which $V_{4}$ was fixed at values in the range from +0.3 to -2.07 $\mathrm{kcal} \mathrm{mol}^{-1}$. Table 5 gives the results of the best fit to the experimental data. The standard deviation for $V_{2}$ increased somewhat compared to that for Model I.

A somewhat better fit was readily achieved through a numerical solution to the integral equation for the probability density $W(\varphi)$ (Model III, Table 5). 


\section{Analysis of the X-ray diffraction data}

All parameters were first refined by least-squares calculations based on all data. However, since the low-angle atomic form factors are rather sensitive to an asymmetry of the valence electrons, the further refinements of the carbon positions proceeded with only those reflections with $\sin \theta / \lambda$ $>0.50 \AA^{-1}$. These reflections are more dependent on scattering from the inner electrons; the resulting carbon positions are thus expected to be closer to the nuclear positions than are those based on the complete data set. Table 6 shows the effect of refinements based on different subsets of the data. The first column shows, for comparison, bond lengths obtained from reflections with $\sin \theta / \lambda<0.65 \AA^{-1}$ (normal CuKa data). The next column contains corresponding data after refinement using all the data. The third column gives the bond lengths obtained using data for $\sin \theta / \lambda>$
$0.50 \AA^{-1}$ only; the fourth column gives these distances after correction for rigid-body motion.

The results allow the following conclusions:

1. There is little difference between the results from refinements using data with $\sin \theta / \lambda<0.65 \AA$ (1987 reflections) and those for the whole data set (2636 reflections).

2. There is a significant difference between results from refinements using high-angle data (1637 reflections) and the two other subsets of data. The high-angle data set indicates a relative expansion of the benzene ring, corresponding to a lengthening of the aryl $\mathrm{C}-\mathrm{C}$ bond by $0.003-0.008 \AA$ and a lengthening of the triple bond by more than $0.01 \AA$. The $\mathrm{C} 1-\mathrm{C} 7$ bond is correspondingly shortened by $0.01 \AA$. The corrections for thermal libration are only about $0.001-0.003 \AA$.

Table 6. Structural parameters obtained from the refinements using various parts of the X-ray data. Atoms of molecule $A$ have first index 1 , those of molecule $B$ have first index 2 . Acetylenic carbon atoms have second index 7. Bond lengths in $\AA$.

\begin{tabular}{|c|c|c|c|c|}
\hline & $\sin \theta / \lambda<0.65 \AA$ & All data & $\sin \theta / \lambda>0.50 \AA$ & Corrected \\
\hline $\mathrm{C}_{11} \cdots \mathrm{C}_{12}$ & $1.399(2)$ & $1.400(2)$ & $1.402(2)$ & 1.405 \\
\hline $\mathrm{C} 11 \cdots \mathrm{C} 16$ & $1.395(2)$ & $1.395(2)$ & $1.401(2)$ & 1.404 \\
\hline $\mathrm{C} 11 \cdots \mathrm{C} 17$ & $1.437(2)$ & $1.436(2)$ & $1.425(2)$ & 1.426 \\
\hline $\mathrm{C} 12 \cdots \mathrm{C} 13$ & $1.383(2)$ & $1.386(2)$ & $1.392(2)$ & 1.393 \\
\hline $\mathrm{C} 13 \cdots \mathrm{C} 14$ & $1.383(2)$ & $1.386(2)$ & $1.389(2)$ & 1.392 \\
\hline $\mathrm{C} 14 \cdots \mathrm{C} 15$ & $1.386(2)$ & $1.387(2)$ & $1.393(2)$ & 1.397 \\
\hline $\mathrm{C} 15 \cdots \mathrm{C} 16$ & $1.387(2)$ & $1.387(2)$ & $1.393(2)$ & 1.394 \\
\hline C17…C17' & $1.194(2)$ & $1.197(2)$ & $1.211(2)$ & 1.212 \\
\hline $\mathrm{C} 21 \cdots \mathrm{C} 22$ & $1.395(2)$ & $1.396(2)$ & $1.401(2)$ & 1.404 \\
\hline $\mathrm{C} 21 \cdots \mathrm{C} 26$ & $1.403(2)$ & $1.404(2)$ & $1.406(2)$ & 1.409 \\
\hline $\mathrm{C} 21 \cdots \mathrm{C} 27$ & $1.435(2)$ & $1.434(2)$ & $1.425(2)$ & 1.426 \\
\hline $\mathrm{C} 22 \cdots \mathrm{C} 23$ & $1.384(2)$ & $1.387(2)$ & $1.394(2)$ & 1.394 \\
\hline $\mathrm{C} 23 \cdots \mathrm{C} 24$ & $1.389(2)$ & $1.390(2)$ & $1.397(2)$ & 1.399 \\
\hline $\mathrm{C} 24 \cdots \mathrm{C} 25$ & $1.386(2)$ & $1.389(2)$ & $1.390(2)$ & 1.393 \\
\hline $\mathrm{C} 25 \cdots \mathrm{C} 26$ & $1.384(2)$ & $1.386(2)$ & $1.394(2)$ & 1.395 \\
\hline $\mathrm{C} 27 \cdots \mathrm{C} 27^{\prime}$ & $1.198(2)$ & $1.201(2)$ & $1.211(2)$ & 1.212 \\
\hline \multicolumn{5}{|l|}{ Average values: } \\
\hline $\mathrm{C} 1 \cdots \mathrm{C} 2$ & $1.398(4)$ & $1.399(4)$ & $1.403(2)$ & $1.406(2)$ \\
\hline $\mathrm{C} 2 \cdots \mathrm{C} 3, \mathrm{C} 3 \cdots \mathrm{C} 4$ & $1.385(2)$ & $1.387(2)$ & $1.393(2)$ & $1.395(2)$ \\
\hline $\mathrm{C} 1 \cdots \mathrm{C} 7$ & 1.436 & 1.435 & 1.425 & 1.426 \\
\hline $\mathrm{C} 7 \cdots \mathrm{C} 7^{\prime}$ & 1.196 & 1.199 & 1.211 & 1.212 \\
\hline$R$ value & 0.036 & 0.046 & 0.044 & \\
\hline$R_{w}$ & 0.042 & 0.050 & 0.045 & \\
\hline$S^{\prime \prime}$ & 1.67 & 1.75 & 1.17 & \\
\hline Scale factor & 0.192 & 0.196 & 0.216 & \\
\hline No. of refl. & 1897 & 2636 & 1637 & \\
\hline
\end{tabular}


Table 7. Fractional coordinates $\left(\times 10^{5}\right)$ of the carbon atoms resulting from the high angle refinement.

\begin{tabular}{lrlr}
\hline Atom & \multicolumn{1}{c}{$x$} & $y$ & \multicolumn{1}{l}{$z$} \\
\hline C11 & $-8060(8)$ & $46804(21)$ & $32865(9)$ \\
C12 & $-13668(9)$ & $26705(23)$ & $28375(11)$ \\
C13 & $-18721(9)$ & $24247(26)$ & $16544(12)$ \\
C14 & $-18293(9)$ & $41713(26)$ & $9126(11)$ \\
C15 & $-12813(9)$ & $61858(24)$ & $13526(11)$ \\
C16 & $-7725(8)$ & $64451(22)$ & $25353(10)$ \\
S17 & $-2511(9)$ & $49081(23)$ & $44915(10)$ \\
C21 & $42282(8)$ & $40489(22)$ & $9125(10)$ \\
C22 & $41991(8)$ & $55618(21)$ & $17667(10)$ \\
C23 & $36796(9)$ & $49366(25)$ & $24095(11)$ \\
C24 & $31779(9)$ & $28092(25)$ & $22005(12)$ \\
C25 & $32003(9)$ & $13095(23)$ & $13482(12)$ \\
C26 & $37264(9)$ & $19036(22)$ & $7086(11)$ \\
C27 & $47670(9)$ & $46978(23)$ & $2658(10)$ \\
\hline
\end{tabular}

3. The corrected high-angle values give a mean value of $1.405(2) \AA$ for the $\mathrm{C} 1-\mathrm{C} 2$ bond lengths in the ring and $1.395(2) \AA$ for the rest of the phenyl $\mathrm{C}-\mathrm{C}$ bonds. The difference is significant.

4. The corrected distances from the high-angle data conform much better with values obtained using methods which measure internuclear separations than do the values derived from lowangle data $(\mathrm{CuK \alpha})$.

Carbon positional parameters obtained from the high-angle refinement are given in Table 7 . Thermal parameters, hydrogen parameters and structure factor tables may be obtained from one of the authors (C.R.) on request.

\section{Discussion}

Potential of internal rotation in the tolane molecule. The advantages and limitations of the use of a dynamic model for determining the potential for internal rotation from electron diffraction data have been already discussed in Refs. 26 and 27.

The tolane molecule is far from being the most favourable subject for such a study, although the experimental conditions $\left(t=150^{\circ} \mathrm{C}\right)$ promote an increase in the population of the higher torsional energy levels. This can be readily seen from the radial distribution curve $\mathrm{f}(r)$, where the $r>5 \AA$ region corresponds to rotation-dependent distances, whose contribution is very small (Fig. 2). The analysis has failed to locate unequivocally the potential function minimum and, hence, the

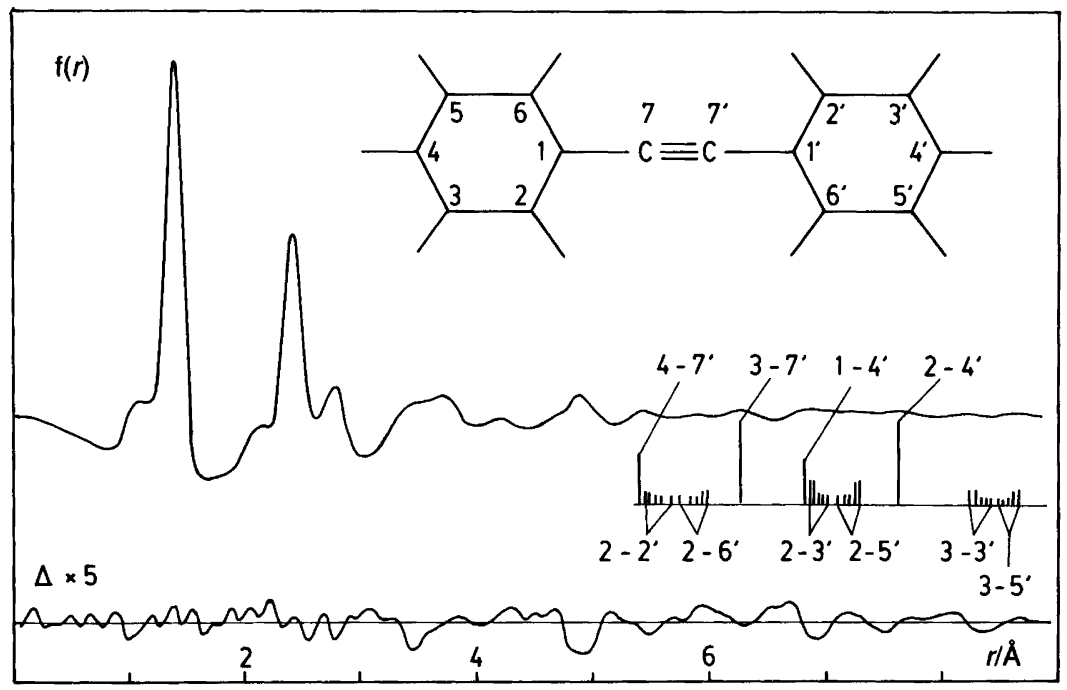

Fig. 2. The experimental $f(r)$ curve for tolane and difference curve for Model I (Table 5). The difference curves for Models II and III have no distinctive features in relation to that for Model I. The damping constant is equal to $0.0012 \AA^{2}$. In the range of the torsion-dependent $C$...C distances $\left.(5.4-8.6) \AA\right)$, the locations and approximate area (length of the bar) of all non-bonded $\mathrm{C} \cdots \mathrm{C}$ contributions are shown. Numbering of atoms is given. 
equilibrium conformation of the tolane molecule. One Fourier expansion term with the $V_{2}$ parameter may suffice for description of the internal rotation potential of this molecule. A solution to the integral equation for $W(\varphi)$ leads to a somewhat different distribution of $P(\varphi)$ in the potential minimum region. This distribution was reproduced by the potential function with two Fourier expansion terms. However, the difference in fit to the experimental data attained in all these cases is not statistically significant.

Since spectral data ${ }^{5}$ were analyzed using the potential function $V(\varphi)=\frac{1}{2} V_{2}(1-\cos 2 \theta)$ which $a$ priori presents a planar conformation, we made some additional calculations in order to reveal whether these spectral data may be adequately described by other potential functions.

The one-dimensional model of internal rotation used for calculations, and the method of solving the respective Schrödinger equations were based on Ref. 28. The calculations according to Ref. 5 were performed within the same approximation.

First, potential form changes on inclusion of higher harmonics were investigated. Calculations with potentials of the form:

$V(\varphi)=\frac{1}{2} \sum_{k=1}^{n} V_{2 k}(1-\cos 2 k \varphi)$,

including up to four terms, revealed that the contribution of the term with the $V_{4}$ coefficient is small (the value of $V_{4}$ is about $1 \%$ of that of $V_{2}$ ), and the coefficients $V_{6}$ and $V_{8}$ do not differ from zero. The experimental energies of transitions are described with an integrated square error of about $0.4 \mathrm{~cm}^{-1}$, ${ }^{*}$ which corresponds to the precision of the experimental data. Thus, the potential curve form is practically sinusoidal. Apparently, this fact excludes the possibility of describing the data by a potential with a different form near the minimum. For example, a flattened bottom of the potential well leads to lower frequencies of torsional vibrations as well as changes in the pattern of level distribution. In fact, a calculation with a model potential with four terms (in kcal $\mathrm{mol}^{-1}: V_{2}=-0.286, V_{4}=0.186, V_{6}=-0.086, V_{8}$ $=-0.057)$, that varies only slightly within the range from 65 to $115^{\circ}$ and corresponds to a barrier height for hindered internal rotation of about
$0.4 \mathrm{kcal} \mathrm{mol}^{-1}$ indicated that the separation between the lower levels is only $4-6 \mathrm{~cm}^{-1}$ (in contrast to the observed value of $34 \mathrm{~cm}^{-1}$ ), the levels proving to be divergent in contrast to the actual situation.

Investigations of potentials with the dominant $V_{4}$ term (non-planar configuration of the molecule with an angle between the phenyl ring planes of about $45^{\circ}$ ) demonstrated that in that case, separations between the levels which are close to the actual separations can be obtained, but the assignment of frequencies in Ref. 5 should be changed. It is assumed that at fluorescence from the states with $v^{\prime}=0,2,4$, transitions to the consecutive levels of the ground state $\left(v^{\prime \prime}=0,1,2 \ldots\right)$ are recorded, and the potential with the two terms (in kcal mol${ }^{-1}: V_{2}=-0.037, V_{4}=-0.598$ ) can describe the observed data with a integral square error of about $0.55 \mathrm{~cm}^{-1}$. In that case, the calculated spectrum displays frequencies that are close to the observed ones at fluorescence from states with $v^{\prime}=1$ and 3 , if they are attributed to transitions of the types $1 \rightarrow 2,1 \rightarrow 3$, etc. However, such assignment is merely formal, and does not provide a reasonable interpretation of the entire set of experimental facts. Hence, the interpretation proposed in Ref. 5 appears to be the only possible one.

Considering the results of electron diffraction analysis from the viewpoint of data in Ref. 5, it appears that priority should be given to Model I (Table 5). It is noteworthy that the barrier height of about $0.58 \mathrm{kcal} \mathrm{mol}^{-1}$ corresponds to placing about 15 vibrational levels in the potential well, owing to which the form of potential can be obtained from the spectral data fairly reliably. However, at a temperature for the electron diffraction experiment of $150^{\circ} \mathrm{C}$, the value of $k T$ is $0.84 \mathrm{kcal}$ $\mathrm{mol}^{-1}$. Under such conditions the torsional motion in the tolane molecule must approach free internal rotation, so that analysis of this form of potential is difficult.

In the case of divinylacetylene, a free rotation model or a potential with a small barrier at $\varphi=$ $90^{\circ}$ are in agreement with electron diffraction data. ${ }^{29}$

These data indicate that conjugation is hardly of major importance in determining conformation in unsaturated systems with a central acetylene fragment.

\footnotetext{
${ }^{*} 1 \mathrm{~cm}^{-1}=2.8592 \cdot 10^{-3} \mathrm{kcal} \mathrm{mol}^{-1}$.
} 
Crystal structure of tolane. The molecular and crystal structure of tolane has been extensively discussed in Refs. 3,6 and 7. The bond lengths and angles obtained in these investigations are compared with the results of the present analysis in Table 8; the reason for the difference in bond lengths is discussed above.

The molecule B $(\mathrm{C} 21-\mathrm{C} 27)$ is planar, the de- viations of the carbon atoms from the leastsquares plane being $0.004 \AA$ or less. In molecule $\mathrm{A}(\mathrm{C} 11-\mathrm{C} 17)$ the phenyl rings are planar, but as discussed in Ref. 3, the acetylenic carbon atom is situated $0.063 \AA$, and the molecular centre of symmetry is situated $0.111 \AA$, out of the plane. No indication of disorder in the molecule $A$ as reported in Ref. 7 was found.

Table 8. Comparison of the results from the structure refinements of the electron diffraction and X-ray data with the parameters available in the literature. Bond lengths in A, angles in degrees. Numbering of atoms corresponds to that given in Fig. 2. The uncertainty corresponds to the least-squares standard deviation.

\begin{tabular}{|c|c|c|c|c|c|c|}
\hline \multirow{3}{*}{$\begin{array}{l}\text { Para- } \\
\text { meter }\end{array}$} & \multicolumn{2}{|c|}{ Electron diffraction ( $r_{\mathrm{a}}$-parameter) } & \multirow{3}{*}{$\begin{array}{l}t-150^{\circ} \mathrm{C} \\
\text { present } \\
\text { study }\end{array}$} & \multirow{2}{*}{\multicolumn{3}{|c|}{$\frac{\text { X-Ray diffraction }}{\text { Room temperature }}$}} \\
\hline & \multirow{2}{*}{$\begin{array}{l}\mathrm{t}=150^{\circ} \mathrm{C} \\
\text { Present } \\
\text { study }^{a}\end{array}$} & \multirow{2}{*}{$\begin{array}{l}t=150^{\circ} \mathrm{C} \\
\text { Refs. } 4 \\
\text { and } 12^{b}\end{array}$} & & & & \\
\hline & & & & Ref. 3 & Ref. 6 & Ref. 7 \\
\hline$C_{1}-C_{21}$ & & & $1.406(2)$ & $1.383(4)$ & & $1.396(3)$ \\
\hline $\mathrm{C}_{1}-\mathrm{C}_{2}$ & $1.400\left(0_{4}\right)$ & $1.398(1)$ & $1.395(2)$ & $1.376(4)$ & $1.401(8)$ & $1.389(3)$ \\
\hline $\mathrm{C}_{2}-\mathrm{C}_{3}$ & average & average & average & $1.367(4)$ & average & $1.383(3)$ \\
\hline$>\mathrm{C}-\mathrm{C} \equiv$ & $1.417(2)$ & $1.425(3)$ & $1.426(2)$ & $1.438(4)$ & $1.401(12)$ & $1.439(3)$ \\
\hline$-\mathrm{C} \equiv \mathrm{C}-$ & $1.215(2)$ & $1.207(3)$ & $1.212(2)$ & $1.198(4)$ & $1.226(3)$ & $1.192(3)$ \\
\hline $\mathrm{C}-\mathrm{H}$ & $1.070(2)$ & $1.082(3)$ & $(0.97(1))$ & & & \\
\hline$\angle \mathrm{C}($ ipso $)$ & $119.3(3)$ & & $119.4(1)$ & $119.1(2)$ & & $119.7(2)$ \\
\hline$\angle \mathrm{C}$ (ortho) & $120.8(2)$ & 120.0 & $120.1(1)$ & $120.1(2)$ & $120(2)$ & $119.9(2)$ \\
\hline$\angle \mathrm{C}$ (meta) & $119.0(3)$ & fixed & $120.3(1)$ & $120.3(2)$ & average & $120.3(2)$ \\
\hline$\angle \mathrm{C}$ (para) & $121.1(3)$ & & $119.9(1)$ & $120.1(2)$ & & $120.0(2)$ \\
\hline$\angle \mathrm{C}-\mathrm{C} \equiv \mathrm{C}$ & 180 (ass) & & $178.0(2)$ & & & \\
\hline
\end{tabular}

${ }^{a}$ Dynamic model. ${ }^{b}$ Static model.

Table 9. Correlations $(\times 100)$ between parameters of Model I of tolane molecule with the rotation potential approximated by one term of a Fourier expansion $V(\varphi)=\frac{1}{2} V_{2}(1-\cos 2 \varphi) .^{a}$

\begin{tabular}{|c|c|c|c|c|c|c|c|c|c|}
\hline & 1 & 2 & 3 & 4 & 5 & 6 & 7 & 8 & 9 \\
\hline 1. $V_{2}$ & 100 & & & & & & & & \\
\hline 2. $\mathrm{C} \equiv \mathrm{C}$ & -1 & 100 & & & & & & & \\
\hline 3. $>C-C \equiv$ & 1 & -28 & 100 & & & & & & \\
\hline 4. $(C \cdots C)_{a v}$ & -4 & 52 & -34 & 100 & & & & & \\
\hline 5. $(\mathrm{C}-\mathrm{H})_{\mathrm{av}}$ & 2 & 19 & -3 & 9 & 100 & & & & \\
\hline 6. $(\mathrm{CCC})_{\text {ipso }}$ & -7 & 23 & 43 & 31 & -10 & 100 & & & \\
\hline 7. $(\mathrm{CCC})_{\text {ortho }}$ & -1 & -16 & -38 & -24 & 8 & -90 & 100 & & \\
\hline 8. Scale ${ }_{50 \mathrm{~cm}}^{b}$ & -1 & -18 & 17 & -16 & -5 & -6 & 13 & 100 & \\
\hline 9. Scale ${ }_{20 \mathrm{~cm}}^{b}$ & -1 & 1 & 11 & -6 & 12 & -4 & 14 & 6 & 100 \\
\hline
\end{tabular}

aThe given correlation matrix is identical to the respective matrix for Model II, with the potential function in the form of $V(\varphi)=1 / 2 V_{2}(1-\cos 2 \varphi)+1 / 2 V_{4}(1-\cos 4 \varphi)$, accurate to the last digit $\left(V_{4}\right.$ is fixed parameter). In the case of Model III [numerical solution for probability density $W(\varphi)$ ], the matrix differs from the preceding ones in the absence of the row and column for the $V_{2}$ parameter. ${ }^{b}$ Relative values of scale factors for the two camera distances are equal to $1.000(4)$ and $1.049(6)$, respectively. 
Geometrical parameters of the tolane molecule in gas and crystal phases. In Table 8 the geometrical parameters of the tolane molecule are compared for two phases. To augment the reliability of such comparison, our X-ray results are those determined on the basis of high-angle data. Taking into account the different physical meaning of structure parameters obtained by electron diffraction and by $\mathrm{X}$-ray methods, the conformity of the results is fairly good. The greatest difference in bond lengths $(0.009 \AA$ for the bond $>\mathrm{C}-\mathrm{C} \equiv)$ is roughly within three-fold standard deviation. Compared with X-ray data, an inversion is obtained of the relative values of the valence angles on the meta and para carbon in the electron diffraction analysis, where they are dependent parameters. This inversion is caused by the use of the weighted average bond length $(\mathrm{C}-\mathrm{C})_{\mathrm{av}}$ for calculation of the phenyl ring geometry. The actual constancy of tolane geometrical parameters in transition from the gas phase to the crystal phase, where the planar conformation is stabilized, is another indication of the small contribution of conjugation to its molecular structure.

The obtained values of the parameters are perfectly normal. The phenyl ring geometry is in good conformity with the respective parameters for the biphenyl molecule. ${ }^{22}$ The lengths of the central $\mathrm{C} \equiv \mathrm{C}$ and $>\mathrm{C}-\mathrm{C} \equiv$ bonds are very close to those of their counterparts in the divinylacetylene and perchlorodivinylacetylene molecules, $\left[r_{\mathrm{a}}(\mathrm{C} \equiv \mathrm{C}) 1.220(2)\right.$ and $1.218(8) \AA, r_{\mathrm{a}}(\mathrm{C}-\mathrm{C} \equiv)$ $1.425(2)$ and $1.415(5) \AA$, respectively] $]^{28}$.

\section{References}

1. Cyvin, S. J., Cyvin, B. N. and Brunvoll, J. Kgl. Norske Videnskab. Selskabs Skrifter (Proceedings of the Royal Norwegian Society of Sciences and Letters) 5 (1982).

2. Liberles, A. and Matlosz, B. J. Org. Chem. 36 (1971) 2710.

3. Mavridis, A. and Moustakali-Mavridis, I. Acta Crystallogr., Sect. B 33 (1977) 3612.

4. Vilkov, L. V., Grumadas, A. J., Kalashnikova, E. V., Kiselev, A. V., Nipan, M. E., Poshkus, D. P. and Sadova, N. I. Abstracts of the VI Symposium on Intermolecular Interaction and Molecular Conformations, Vilnius 1982, p. 111.

5. Okuyama, K., Hasegawa, T., Ito, M. and Mikami, N. J. Phys. Chem. 88 (1984) 1711.

6. Samarskaya, V. D., Myasnikova, R. M. and Kitaigorodskii, A. I. Kristallografiya 13 (1968) 616.
7. Espiritu, A. A. and White, J. G. Z. Krist. 147 (1978) 177.

8. Suzuki, H., Koyano, K., Shida, T. and Kira, A. Bull. Chem. Soc. Jpn. 55 (1982) 3690.

9. Kellerer, B., Hacker, H. H. and Brandmüller, J. Indian J. Pure Appl. Phys. 9 (1971) 903.

10. Baranovic, G., Colombo, L. and Skare, D. J. Mol. Struct. 147 (1986) 275.

11. Bobrov, A. V. and Sterin, Kh. E. Opt. Spektrosk. 17 (1964) 625.

12. Nipan, M. E. Dissertation, Department of Chemistry, Moscow State University, Moscow 1982.

13. Cyvin, B. N. and Cyvin, S. J. Unpublished results.

14. Bastiansen, O., Hassel, O. and Risberg, E. Acta Chem. Scand. 9 (1955) 232.

15. Andersen, B., Seip, H. M., Strand, T. G. and Stølevik, R. Acta Chem. Scand. 23 (1969) 3224.

16. Bonham, R. A. and Schäfer, L. In: Ibers, J. A., Ed., International Tables for X-ray Crystallography, Kynoch Press, Birmingham 1974, Vol. IV. Sect. 2.5.

17. Tavard, C., Nicolas, D. and Rouault, M. J. Chim. Phys. 64 (1967) 540.

18. Fernholt, L., Rømming, C. and Samdal, S. Acta Chem. Scand., Ser. A 35 (1981) 707.

19. Syschikov, Yu. N., Vilkov, L. V. and Yagola, A. G. Vestn. Mosk. Univ. Khim. 24 (1983) 541.

20. Tikhonov, A. N. and Arsenin, V. Ya. Metody Resheniya Nekorrektnykh Zadach, Nauka Press, Moscow 1986; Tikhonov, A. N. and Goncharsky, A. V. Ill-Posed Problems in the Natural Sciences, MIR Publishers, Moscow 1987.

21. Gundersen, G., Samdal, S., Seip, H. M. and Strand, T. G. Least-Squares Structural Refinement Program Based on Gas Electron Diffraction Data. Part 1-4. Program Description. University of Oslo, Norway, Oslo Internal report 1980/1981.

22. Almenningen, A., Bastiansen, O., Fernholt, L., Cyvin, B. N., Cyvin, S. J. and Samdal, S. J. Mol. Struct. 128 (1985) 59.

23. Cyvin, S. J., Cyvin, B. N., Brunvoll, J., Whitmer, J. C., Klæboe, P. and Gustavsen, J. E. Z. Naturforsch., A 34 (1979) 876.

24. Cyvin, B. N., Neerland, G., Brunvoll, J. and Cyvin, S. J. Z. Naturforsch., A 35 (1980) 731.

25. Kellerer, B. and Hacker, H. H. J. Mol. Struct. 13 (1972) 79.

26. Bastiansen, O. and Samdal, S. J. Mol. Struct. 128 (1985) 115.

27. Syschikov, Yu. N., Batyukhnova, O. G., Vilkov, L. V. and Yagola, A. G. In: Krasnov, K. S., Ed., Issledovanie Struktury i Energetiki Molekul, I. Kh. T. I. Press, Ivanovo 1986, pp. 64-73.

28. Lewis, J. D., Malloy, T. B., Chao, T. H. and Laane, J. J. Mol. Struct. 12 (1972) 427.

29. Almenningen, A., Gogstad, E., Hagen, K., Schei, H., Stølevik, R., Thingstad, $\emptyset$. and Trætteberg, M. J. Mol. Struct. 116 (1984) 131.

Received January 25, 1988. 